\title{
El Peritaje Médico en la Legislación Peruana
}

\author{
Por el Doctor DOMINGO GARCIA RADA, \\ Vocal de la Corte Superior de Lima, Catedrático de las \\ Universidades Católica $\mathbf{y}$ de San Marcos
}

En el campo del Derecho dos principios contradictorios se disputan Ia primacia: el Derecho del Estado - que es también Deber- a imponer e! orden público indispensable para la convivencia social; el Derecho de la Persona Humana a su libertad, honor e integridad. Es necesario el equilibrio armónico de estos principios, pues si prevalece la Persona sobre el Estado, volvemos a la época primitiva en que cada indiviciuo se hacía justicia por sus manos; pero si prevalece el Derecho del Estado sobre el Individuo puede llegarse a la tiranía. La base esencial para alcanzar este equilibrio es la existencia de un proceso penal técnicis y justo, en el cual convivan el derecho del Estado con el respeto debido a la persona humana.

\section{I.-El Proceso Penal Perucno.}

El Derecho Penal vive una verdad limitada, humana, sujeta a errores. Para alcanzar esta verdad existe el Proceso Penal. Para remediar los errores tenemos el Recurso de Revisión.

El fin del proceso penal es alcanzar la verdad legal. Entre lo probado y lo verdadero, por lo general, existe estrecha correlación: sin embargo no todo lo probado es verdadero ni toda verdad es susceptible de probanza. Por eso lo probado es relativo y contingente. La diferencia entre lo probado y lo verdadero explica los errores judiciales. No toda prueba conduce a la verdad, pues a veces puede intentarse probar lo falso. Como método de prueba, el proceso cuenta con la Técnica, que es medio al servicio del fin, cual es realizar el Derecho.

El Proceso Penal regula la Prueba, la cual está al servicio del Derecho. Su contenido está limitado por el Derecho al cual sirve. Si en algún momento escapa a esta finalidad, ya no es útil. El medio nunca puede so-brepasar al fini su alcance está determinado por el fin al cual aspira. $\mathrm{Si}$ Ia Prueba sirve al Derecho, está delimitada por el Derecho; es decir la Frueba será buena mientras cumpla su finalidad, en el momento en que

•1) Trabajo presentado al Primer Congreso Hispanoamericano de Derecho Penal (Madrid, 1952). 
se extralimite de los fines del Derecho, entonces ya no sirve al Derecha. sino lo contrario. Lo que se trata en un proceso penal es la realización del Derecho que representa intereses generales y permanentes. Si una pruebu por servir a finalidad transitoria, vulnera los principios eternos del Derecho. esa ya no es prueba apta para un proceso penal.

Debe quedar establecido que la finalidad del Proceso es alcanzar la verdad real; que para éste logro cuenta con la Prueba y que ésta sirve al Derecho, no el Derecho a ella; de manera que la. prueba es buena en cuanto cumpla su finalidad y debe rechazarse si atenta contra los principios permanentes del Derecho.

Las pruebas son los medios mediante los cuales el Juez obtiene las experiencias que le sirven para juzgar. Carnelutti las compara a las llaves mediante las cuales el Juez trata de abrir las puertas de lo desconocido. La prueba única es débil; en un debate casi nunca el Juez se apoya en una sola prueba, se sirve de varias. Esta pluralidad de pruebas destinadas a establecer un mismo hecho, es lo que se denomina Concurso de Pruebas cuyos elementos son: "la multiplicidad de las pruebas y la unidad del therna probandi".

Estos principios de carćcter doctrinario están røconocidos en la ley procescl peruana. Es el período investigatorio en que procede la prueba de los hechos incriminados. El $\alpha \mathrm{rt}$. 72 declara cual es el objeto de la instrucción al decir: "La instrucción tiene por objeto reunir la prueba de la realización del delito, las circunstancias-en que se ha perpetrado, sus móviles y dascubrir a los autores y cómplices del mismo, estableciendo la distinta participación que haycin tenido en los actos preparatorios, en la ejecución o después de su realización, sea para borrar las huellas que sirvan para su descubrimiento, para prestar auxilio a los responsables, o para aprovecharse en alguna forma de sus resultados".

Aicanzada esta finalidad, el Juez daró por concluída la instrucción. sm espercr el vencimiento del plazo legal, pero si venciere ésłe, sin reunir las pruebas pertinentes deberó pedirse uno especial ampliatorio. El art. 196 dice: "La instrucción se dará por concluída cuando el juez haya acumulado los elementos suficientes para llenar el objeto de ella conforme al art. $72^{\prime \prime}$.

El proceso penal presume que el imculpado es inocente, presunción que solo se destruye mediante pruebas. Siendo inocente tiene derechos que merecen respeto y consideración de parte de la autoridad judicicl. Considerado en el proceso y para realizar los tines de la investigación, el imputado sufre limitaciones en su libertad, que no afectan la integridad física o síquica de su persona. Declarado culpable, siempre es persona humana para la ley penal, explicándose así que uno de los fines de la pena, sea procurar la readaptación del condenado; finalidad que carecería de objeto si no fuera persona. 
Dentro del equilibrio que debe existir entre los derechos de la so. ciedad para perseguir los delitos y los del encausado, se encuenira el proceso penal que respeta lo fundamental de los derechos humanos, $y$ limita aquellos cuando lo considera indispensable para la investigación, v. $\}$. puede impedir la salida del territorio nacional, obligarlo a comparecer periódicamente al Juzgado o Tribunal, etc. Son cortapisas que, sin atentar contra la personalidad del encausado, garantizan el derecho de la socielad a perseguir a los culpables de delitos. Establecida la responsabilidad, estas limitaciones se convierten en restrictivas de la libertad y del patrimonio. Entonces pierde su libertad pero no su integridad física. Aun sufriendo esta disminución de sus derechos, siempre es persona humana, que permanece intacta en todo aquello que es inviolable. Aun como enccusado, tiene derechos. v. g. la ilimitación de la defensa, la correlación entre la pena, el delito y la responsabilidad, etc.

En el Perú estos principios de respeto a la personalidad del encausado y de garantías a los derechos de la sociedad, se encuentran reconocidos en el Código de Procedimientos Penales.

Así el art. 79 establece que el "El Juez Instruclor puede dictar orden de comparecencia o de detención contra el que presume culpable". La presunción de culpabilidad es suficiente para que el Juez dicte orden de detención. El art. 84 ratifica este principio ol disponer que "si el juez instructor presume la culpabilidad, dictará orden de detención definitiva contxa el inculpado". La libertad y detención del enccusado están a merced ciel criterio del Juez, dentro de los límites de la ley. Es la tendencia moderna a darle plsna cutcridad en la investigación de los delitos.

En cuanto al resarcimiento económico del daño causadio por el delito, el ari. 94 establece que "Como consecuencia de la detención definitiva que se haya dictado, el juez procederá al embargo preventivo de los bienes del inculpado que sean bastantes para cubrir la responsabilidad civil". Son las dos restricciones que exige la sociedad y que la ley procesal penal contempla: a la libertad humana y al patrimonio.

En cuanto a los derechos del inculpado, el art. 85 ordena que "La instructivo deberá ser tomada o cuando menos comenzada por el Juez Instrucior antes que se cumplan 24 horas de la detención". Así se garontiza la rapidez en la justicia pora establecer la situación jurídica de los detenidos por delitos. Para rendir esta declaración, la ley exige que esté amparado por defensor, o por lo menos que sepa que le csiste este derecho: el art. 121 dice "Antes de tomar la declaración instructiva, el juez instruc. tor hará presente al inculpado que tiene derecho a que lo asista un defensor y que si no lo designa, será nombrado de oficio. Si el inculpado conviene en esto último, el juez instructor hará la designación de abogado o. a falta de éste, de persona honorable. Pero si el inculpado no acepta tener defensor se dejcrá constancia en cutos de su negativa, cuya diligencia deberá suscribir. Si no sabe leer y escribir o es menor de edad, el juez le nombrará defensor indefectiblemente". La protección de la ley llega al extremo que, si ello fuera necesario, deberá suspenderse la diligencia danco tiempo al letrado designado por el inculpado para que se haga cargo de su defensa, concesión que solo puede darse dentro de los plazos legales. es decir tomar la instructiva dentro de las 24 horas (art. 123). Es la pri- 
mera garantía que la ley reconoce al inculpado: estar asistido por abogado y no cerrar la diligencia instructiva sin que este profesional se encuentre presente y lo asesore en su declaración.

En cuanto al interrogatorio propiamente dicho, el art. 124, después de exigir que el juez pregunte por sus generales, agrega "Lo invitará en seguida a que exprese donde, en compañía de quienes y en que ocupación se hallaba el día $y$ hora en que se cometió el delito $y$ todo cuanto sepa respecto al hecho o hechos que se le imputan y sus relaciones con los agraviados". Esta redacción indica a las claras la consideración que el juez debe guardar con una persona a quien se presume inocente.

"Las preguntas hechas al inculpado no serán obscuras, ambiguas ni capciosas" (art. 125). La claridad $y$ el orden en el interrogatorio están especialmente mandadas por el legislador para evitar que se sorprenda al encausado; si el juez hiciere tal cosa, el defensor puede "aclararlas u cbservarlas" según lo dispone el art. 126. Ante el silencio del inculpado "el juez la repetirá, aclarándolas (las preguntas) en lo posible, y si aquel inantiene su silencio, se dejará constancia en la diligencia". (art. 127). Si el inculpado tuviere cápacidod para ello, el juez puede autorizarlo a diciar sus respuestas y en todo caso leerlas antes de firmar (art. 129).

Esta forma de desarrollar el interrogatorio demuestra que la intención àel legislador es rodear al inculpado de toda clase de garantías, evitando que sea sorprendido y asegurando la más absoluta fidelidad en el acta. Completa el cuadro trazado por el código, el art. 138 que dice: "Se prohibe en absoluto el empleo de promesas, amenazas $u$ otros medios de coacción, aunque sean simplemente morales. El juez debe exhortar al in culpado para que diga la verdad; pero no podrá exigirle juramento ni pro mesa de honor". Este último artículo autoriza al inculpado a mentir en defensa propia. Nadie está obligado a acusarse. La persuación para que diga la verdad es lo único que la ley admite. El respeto a la persona humana llega al extremo de prohibir terminantemente toda coacción moral. EJ encausado debe proceder con absoluta espontaneidad y declarar en la forma que mejor viere convenirle.

Del examen detenido de estos artículos, se desprende que la orientación seguida por nuestros legisladores ha sido de máximo respeto a la integridad física y moral de los inculpados, $\alpha$ quienes se presume inocentes y solo después de una condena es que la ley los reputa culpables. Mientras está enjuiciado, sufre limitaciones, quedando intactos sus derechos humanos; - sentenciado aumentan las restricciones, pero permanece inviolada su dignidad humana. De este modo nuestra ley procesal penal manitiesta su adhesión a los principios espiritualistas que informan la Civilización Occidental.

\section{II.- El Peritaje Médico-Legal.}

Cuando la valoración de las pruebas exige idoneidad técnica que el Juez no posee, se nombrarán peritos. En primer lugar, el perito opera para la reunión de las pruebas, esto es, para la búsqueda de las mismas y para su exacta observación. 
El Juez puede proceder al nombramiento de peritos de oficio; la razón está en la insuficiencia técnica del juez para valorar ciertas pruebas reajes. El perito asesora al Juez en la percepción de estas pruebas.

Para que el Juez se forme convicción frente a ciertos hechos cuya solución requiere conocimientos especiales, que no posee, es indispensable la interpretación de los mismos. De allí la necesidad de que en tales circunstancias cuenten con el auxilio de los especialistas. Esta colaboración del técnico con la administración de justicia, es lo que se llama "Peritaje Judicial" y quien lo realiza es el Perito. Cuando se trata de problemas relacionados con las ciencias médicas, se solicita el asesoramiento de profesionales médicos, llamándose "Peritaje Médico-Legal" el documento que ellos emiten a pedido del Juez.

El peritaje médico-legal es el aporte de la ciencia médica al discernimiento de la justicia, función de suma importancia técnica y de gran trascendencia moral. La pericia médica exige que el profesional llene dos requisitos: preparación técnica y solvencia moral. No se puede ser buen perito si falta alguna de ellas. Es deber del perito decir la verdad. Para ello debe saber encontrarla $y$ luego quererla decir. Por eso se dice que el penito médico se encuentra frente $\alpha$ dos situaciones: una de carácter científico: el hallar la verdad; $y$ otra de carácter moral: el decir la verdad encontrada.

Sobre la condición de estos colaboradores de los jueces, existe controversia. Muchos autores estiman que los peritos son auxiliares de la administración de justicia, porque mediante sus conocimientos, el juez adquiere convicción sobre ciertos hechos, realizando una función ilustrativa; pero Iittermaier con razón afirma que si bien es cierto que en muchos casos ocurre tal cosa, en cambio en otros el perito tiene funcićn principalísima, determinando la existencia del delito, v. g. cuando emite juicio sobro el envenenamiento de las vísceras, sobre el estado de preñez, sobre las lesiones sufridas for la víctima, etc. En estos últimos casos, el perito no realiza función ilustrativa, sino algo más: da un juicio que a menudo es definjtivo para el encausado y que el juez deberá aceptar por su evidencia. Por esc, la condición de los peritos es especial: ilustran algunas veces, pero en otros casos, al comprobar la existencia de determinado fenómeno humano o social, determinan el giro de la instrucción.

La fuerza probatoria de los peritajes radica en los motivos de credibiIidad: ciencia y honestidad. Cuando el Juez designa peritos, es porque corlía $\in$ n sus conocimientos y en su moralidad y al otorgarle crédito a su dicho, adquiere certeza legal en ese punto.

La ley procesal penal no contiene ninguna disposición que fije el valor probatorio del peritaje. Como la testimonial, esta prueba está sometida a la apreciación personal del juez, con arreglo a la lógica y a la sana crítica. En esta apreciación, el Juez deberá tener presente las siguientes circunstencias:

10-La competencia de los peritos, ya determinada por el propio juez al nombrarlos, en que ha calificado su ciencia $\mathrm{Y}$ honestidad;

2:-El contenido del dictamen. Es necesario examinar el contenido del dictamen para establecer: 
a) si se fundamenta en leyes científicas constantes, o sujetas a contradicción;

b) si las deducciones son lógicas o arbitrarias;

c) si la motivación es sólida o inconsistente;

$3^{\circ}$-Si existe uniformidad entre los peritos; si hay disconformidad. ver si ésta es accidental o versa sobre el fondo del asunto;

$4^{\circ}$ - Si los principios científicos en que se funda ofrecen garantías por su solvencia y seriedad;

$5^{\circ}$-Si existe concordancia entre el peritaje, las otras pruebas y los clemás elementos de convicción del proceso.

Apreciando estos elementos el Juez se formará convicción sobre el valor procesal del peritaje médico-legal.

Si bien en algunos casos el peritaje es definitivo, por lo general sti valor probatorio está supeditado a la concordancia con las demás pruebas. Será capreciado según los elementos ya indicados. El fin del peritaje es formar convicción en el ánimo del juez, no sustituirse al juez. En ningún caso el perito reemplaza al Juez ni el peritaje a la sentencia. Además al conocerse el peritaje, ya se conocería cual va a ser el sentido del fallo.

La oportunidad para designar peritos la establece el Código en el art. 160 que dice: "El Juez Instructor nombrará peritos cuando en la instrucción sea necesario conocer o apreciar algún hecho importante que requiera conocimientos especiales. Este nombramiento se comunicará al inculpado, al Ministerio Público y a la parte civil".

En cuanto a su número, el art. 161 dice: "Los peritos serón dos, y el Juez instructor deberá nombrar de preferencia a especialistas donde los hubiere $y$, entre éstös, $a$ quienes se hallen sirviendo al Estado. A falta de profesionales nombrará a personas de reconocida honorabilidad y competencia en la materia". Al nombrarse peritos, el Juez les señalaró el plaz? necesario "cuidóndose de que éste sea suficiente", dice el art. 162. Si demoran la entrega del dictamen "serán compelidos a emitirlo dentro de 48 horas" (art. 163). Para tachas y excusas se aplican las reglas de los testigos (arts. 164 y 165).

"El inculpado y la parte civil pueden nombrar por su cuenta, un perito, cuyo dictamen se añadiró a la instrucción", dice la última parte del art. 165. Este documento requiere ratificación, teniendo función ilustrativa. Su valor probatorio, al igual del emitido por los peritos oficiales del Juzgado, será apreciado por el Juez conforme a los principios establecidos.

Solo en casos urgentes, la ley procesal acepta que el reconocimiento de huellas recientes sea practicado por un perito en plazo mínimo, dictamen que deberá ser apreciado por los peritos designados por el Juzgado en la forma ordinaria. Tal es la disposición del art. 166: "Si las circunstancias exigen un inmediato reconocimiento por temor de que se borren las huellas del delito, el juez instructor podrá ordenar que lo practique uno o dos peritos. En este caso no es necesario citación alguna, y la operación deberá practicarse dentro de las 24 horas. El dictamen emitido en esta forma podrá ser sometido al estudio de otros peritos, designados conforme a los artículos anteriores, los cuales, a su vez, reconocerán, en cuanto seci posible, las cosas que fueron materia del primer dictamen. Para el examen 
que debe seguir a la entrega de los informes, serán también citados los peritos que hicieron el primer reconocimiento".

Verdadera importancia reviste la diligencia de ratificación del dictamen pericial, en la cual se abrirá debate para esclarecer circunstancias $Y$ llegar $\alpha$ conclusiones ciertas y definitivas. El Art. 167, que trata de esta diligencia, es explícito: "Los peritos entregarán, personalmente. sus dictóme. nes al juez instructor, quien, en ese mismo acto, les tomará juramento o promesa de decir la verdad y los examinará como si fuesen testigos, pre. guntándoles si ellos son autores del dictamen que presentan, si han procedido imparcialmente en el examen $y$ en la información que suscriben, $y$ todas las circunstancias que juzque necesario aclarar y que se deriven, ya de los hechos que se conocen por la instrucción, ya de los que resulten de los dictámenes. Si hubiere contradicción en los dictámenes, el juez abrirá un debate, en que cada uno de los peritos exponga los motivos que tiene para opinar como lo hace, debiendo el juez exigirles que redacten en sintesis, los argumentos expuestos. Los peritos no pueden negarse a dar las explicaciones que el juez les pida". Este examen de los peritos es obligatorio, conforme lo dispone el Art. 168, estando cutorizados a concurrir el inculpadc, su defensor, el Ministerio Público y la parte civil, quienes pueden Fedir aclarciciones sobre el dictamen. A diferencia de los perilos en un pro ceso civil, que deben previamente aceptar y jurar el cargo, en la instrucción al juramento es, como ya hemos visto en la diligencia de ratificación.

Establecida la forma cómo la ley procesal penal peruana regula la pericia, veamos ahora en qué casos intervienen los peritos médicos, así como su actuación.

a) Autopsic.-En los casos de muerte violenta o sospechosa, el Juez frocederá al levaniamiento del cadáver, lo que equivale a un reconocimisnto externo del mismo, ordenándose luego la cutopsia. Para realizar ésta, el médico debe contar con la cooperación de dos ayudantes: uno que lo auxilie en la autopsia propiamente dicha, y otro que vaya escribiendo las com. piobaciones a medida que éstas se produzcan. Cuando no es posible contar sino con un ayudante, debe sacrificarse al primero, pues el médico no puede confiar en su memoria las observaciones que vaya haciendo conforme realiza su tarea y éstas son definitivas.

Ordinariamente, la dutopsia la practican los médicos de la Morgue, pero en casos graves, en que se presume delito, la ley dispone que el juez nombre peritos médicos, quienes presenciarón la autopsia para emitir el dictamen correspondiente. Tal es el sentido del artículo número 172: "En la instrucción por causa de muerte violenta o sospechosa de criminalidad, el juez y los peritos harán el reconocimiento del cadáver, antes de la inhumación; $Y$ el juez ordenará que se practique la autopsia, en su presencia, por los peritos nombrados conforme al título respectivo, y solicitará de éstos las aclaraciones que juzgue necesarias, levantando acta de la diligencia". El Art. 176 agrega que en determinadas circunstancias puede invitarse al médico que atendió al finado durante su última enfermedad, $\alpha$ que presencie la autopsia "para dar las informaciones técnicas sobre el curso de la enfermedad". Este aporte ilustrativo del profesional de la familia puede dilucidar muchos puntos obscuros, contribuyezido decisiva- 
mente al esclarecimiento de los hechos. La presencia del inculpado y de su defensor en la cutopsia, es facultativa, pero "el juez dejará constancia de las observaciones que formulen en esa diligencia" (Art. 177), las que uparecerán en el acta respectiva.

Para que la autopsia llene su finalidad, deberó reunir los siguientes requisitos: 19, debe ser metódica. es decir, no olvidar ninguna de las com. probaciones que está obligada a efectuar $Y$ que más tarde puedan tener suma importancia en el curso del proceso; $2^{\circ}$, debe ser completa, es decir, debe comprender el examen de las tres grandes cavidades del organismo humano, a saber: la craneal, la pectoral y la abdominal, así como de los miembros (músculos y huesos); $3^{\circ}$, debe ser descriptiva, dictando el médico todo cuanto le es dado ver, especificando forma, color, dimensiones, situación, peso, etc., de los diversos órganos examinados. Estos principios coctrinales están recogidos en el Art. 179, que dice: "La autopsia deberó comprender siempre la apertura de las cavidades craneal, pectoral y ab. dominal. También se extendeŕ́ en los casos necesarios, a juicio del juez instructor, $y$ siempre que sea practicable, a la cavidad raquidea $y$ cualesqujera órganos que deberán examinarse detallada y metódicamente, conforme a las indicaciones científicas. Cuando se trata de la autopsia de un recién nacido, se examinará si ha vivido después o durante el nacimiento, sj había llegado al completo desarrollo y si nació en condiciones de viabilidad".

Al realizar una autopsia, el médico debe tener presente dos circunstancias: 19 , que el protocolo de autopsia es la base del proceso, que servirá de apoyo a la sentencia que se dicte y que durante el curso de la instrucción va a ser objeto de ataques y aun de una contra-pericia, así como del interrogatorio en la diligencia de ratificación, todo lo cual debe llevar al médico a ser lo más exacto posible, poniendo todo lo que ve y nada más; $2{ }^{\circ}$, que es imposible recomenzar una autopsia mal comenzada ni volverla $a$ realizar, pues la circunstancia de tener pocas horas de fallecido, facilita la comprobación de huellas en el cadáver, las mismas que desaparecen con la descomposición natural.

De la diligencia de autopsia, el juez levantará el acta respectiva, inestimable documento judicial, en el cual constarón las comprobaciones des los funcionarios de la Morgue, las observaciones de los peritos médicos, las aclaraciones del médico de la familia, y las atingencias -si las hubieredel inculpado, su defensor y las propias del juez y del Ministerio Público.

b) La Exhumación es el acto de retirar un cadáver del correspondiente ataúd empleado para la inhumación en tierra, bóveda, nicho, eic. Cuando se efectúa por orden judicial, tiene por finalidad practicar la cutopsia destinada a establecer la causa de la muerte.

I a exhumación no ofrece la simplicidad de la autopsia. Grave inconveniente es la putrefacción, o sea, "la descomposición de las materias albuminoideas con producción de gases pútridos", según definición de Balthazard. Es un fenómeno cadavérico cuya iniciación no es inmediata a la 
muerte y varía según la causa del fallecimiento, la estación del año, la temperatura ambiente, etc. El punto de partida de esta descomposición es el intestino, de donde se difunden los microbios por el resto del organismo. Las partes del cuerpo se descomponen en forma desigual, transformóndose en membranas amorfas; las blancas desaparecen $y$, al cabo de dos a cuatro años, sólo queda el esqueleto. Ha quedado establecido que dos cadáveres no se pudren jamás de la misma manera, aun cuando la putrefacción tenga lugar en el mismo medio, pues intervienen factores difíciles de precisor.

Para los efectos médico-legales, debe tenerse presente que la putrefacción dificultc. $y$ a veces imposibilita las comprobaciones de la autopsia. Sólo en el caso de traumatismos, la exhumación alcanza resultado positivo, pues la buena conservación del esqueleto puede dar datos concretos y definjtivos en orden a la comprobación del delito. A pesar de estas dificultades, tiene que recurirse a la exhumación cuando el delito se descubre después de varios días de fallecida la víctima, pues es el único medio de comprobar si aún existen huellas en el cadáver.

Desde el punto de vista procesal, para la exhumación se procederá de igual manera que con la autopsia, interviniendo peritos en la forma indicada. También requiere sentarr acta de cuanto se constate en la diligencia, cuyo valor probatorio es grande. Como exigencia oportuna, la ley manda que esta diligencia se realice a la brevedad posible.

El Código de Procedimientos Penales trata de esta prueba en el Art. 178, que dice: "Si el delito ha sido denunciado o se descubre después de Ia inhumación, el juez instructor ordenará la exhumación y llevará a cabo

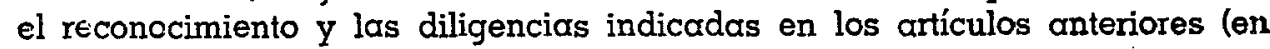
que trata de la autopsia) en cuanto sea posible".

c) En el caso de Envenenamiento, el examen pericial tendrá por objeto determinar si la víctima ha sucumbido por efecto del veneno. Los peritos deben comenzar por practicar un examen externo del cadáver y com. probar si presenta alguna huella visible de envenenamiento; luego procederán $\alpha$ abrirlo para averiguar la acción interna del veneno en los diversos ćrganos. Este examén interno revestirá el carácter de una cutopsia cuya finalidad será comprobar la presencia del tóxico en el organismo. Hallados los residuos del veneno en alguna víscera, debe procederse al análisis químico de la misma, para cerciorarse de la presencia de la sustancia extraña, señalarla con precisión, establecer su posible acción sobre el cuerpo humano y determinar si este veneno es la única causa de la muerte, si solamente es causa concurrente o si el deceso de la víctima obedece a otros motivos.

Para la realización de esta pericia, es indispen zuble contar con un Laboratorio Toxicológico encargado de la práctica de estas primeras investigaciones científicas que deberán procurar la prueba inicial del delito. Este Laboratorio deberł́ contar en su personal, a un médico laboratorista especializado y a un químico; los preparadores $\mathrm{y}$ auxiliares no tienen por qué poseer la calidad científica de los primeros, pues son meros ayudantes. 
Este Laboratorio tiene una misión delicada e importante, porque mediante su dictamen se establece si la víctima ha muerto por acción del veneno o por otra causa. Esta prueba orientará el curso del proceso.

El examen toxicológico de las vísceras y demás materias sospechosas, se realiza a base de reactivos $y$ sustancias químicas para establecer lc presencia del veneno, su acción sobre el organismo y su eficacia. El ćocumento redactado por los peritos técnicos, debidamente ratificado, es unra de las pruebas de mayor valor.

El Art. 180 se refiere a esta prueba y dice lo siguiente: "Si existen indicios de envenenamiento, los peritos examinarán las vísceras y las materias sospechosas que se encuentren en el cadáver o en otra parte y las remitirán en envases aparentes, cerrados y lacrados, al laboratorio de criminología de la Policía Judicial. Las materias objeto de las pericias se conservarán, si fuese posible, para ser presentadas en el debate oral".

Al decir el artículo "o en otra parte" quiere significar que este excrmen también comprende los residuos que puedan hallarse en pomos, tras$\cos _{\text {, }}$ recipientes, etc., antes usados por la víctima.

d) Al referirse a las Lesiones, nuestro Código Penal establece las siguientes: heridas "que ponen en peligro la vida" (Ârt. 165 lesiones graves $Y$ previsibles (Art. 166); lesiones mortales y previsibles (Art. 166); lesiones graves, imprevisibles e involuntarias (Art. 167); $y$ lesiones corporales por regligencia (Art. 168). Dada esta variedad en la forma y gravedad de la: lesiones, es indudable que el peritaje médico reviste importancia, por cuanto determina la mayor o menor responsabilidad del inculpado.

Desde el punto de vista médico-legal, es frecuente dividir las lesiones según la clase del agente traumatizador; así tenemos las ocasionadas por armas cortantes, punzantes, punzo-cortantes, armas de fuego, explosiones, quemaduras, por electricidad, etc. Cada una de ellas reviste distinta gravecad variando asimismo la responsabilidad del agente. Esto revela la importancia que tiene el peritaje para establecer la participación del agente, la preparación del mismo mediante la adquisición del instrumento o la ocasionalidad, como lo obtuvo y el modo de su empleo, todo lo que revela la ma. yor o menor peligrosidad del actor.

En el caso de heridas causadas voluntariamente, el peritaje deberó determinar la naturaleza de las lesiones, sus efectos sobre el herido, si hat habido alguna causa concurrente que le dé mayor gravedad o si la constítución física de la víctima ha contribuído al agravamiento. Para la apreciación de las heridas, el perito tomará en cuenta la forma y circunstancias en que se ocasionaron, la posición de los actores, la constitución física de los mismos, los instrumentos empleados, etc.; determinará la gravedad de las lesiones y estableceró el tiempo de asistencia médica necesario para la curación del herido $\mathrm{y}$ el de descanso absoluto hasta su total recuperación; e indicará si las heridas dejarán señales visibles e indelebles, si tendrán consecuencias ulteriores, si el rostro quedará desfigurado, etc. Es decir, to dos cquellos elementos que servirán al juzgador para calificar el delito $Y$ establecer la responsabilidad del autor. 
El Art. 181 es explícito al establecer lo siguiente: "En caso de lesiones corporales, el juez instructor exigirá que los peritos determinen en su informe el arma o instrumento que las haya ocasionado y si dejaron o no deformaciones y señales permanentes en el rostro, puesto en peligro la vida, causado enfermedad incurable o la pérdida de algún miembro $u$ órgano $y$, en general, todas las circunstancias que, conforme al Código Penal, influyen en la calificación del delito".

e) El Aborto es la interrupción provocada del embarazo, con la muerte del feto. Sus elementos son: la interrupción del embarazo; y como consecuencia de esto, la muerte del feto.

En Obstetricia suele hacerse la distinción entre parto prematuro (expulsión del embrión en los tres últimos meses); y aborto (expulsión en los primeros seis meses). En Medicina Legal esta distinción carece de interés, for no modificar sustancialmente la calificación del hecho delictuoso. Cuancio se trata de delito, es importante establecer la expulsión provocada del feto, no bastando acreditar la interrupción del embarazo.

El diagnóstico del aborto es problema esencialmente médico $y$, por consiguiente, de la incumbencia exclusiva de los peritos nombrados con tal fin. El peritaje deberá esclarecer estos puntos: $1^{\circ}$, si ha habido aborto; $2^{9}$, clál es su origen; $3^{\circ}$, época del embarazo en que se produjo. Para formular diagnósticos es indispensable practicar el examen físico de la madre, determinar la fecha del aborto, fijar las condiciones en que ocurrió, la hemorragia sufrida, los caracteres que presentaban los órganos genitales después de realizada la expulsión del feto, las condiciones higiénicas, etc. Deberá Frocurarse hallar el instrumento que sirvió para consumar el delito, lo cual no siempre es posible. En cuanto al feto, tiene importancia pericial establecer la existencia de lesiones traumáticas ocasionadas por la sonda metálica, la cureta, etc., huellas no siempre fáciles de hallar y que muchas veces no pueden darse por no haberse empleado instrumentos metálicos en la realización del aborto. Dato importante para formular el diagnóstico, es compro bar si ha habido hemorragia, la que casi siempre es posterior en los abortos provocados, a la inversa de lo que ocurre en los ocasionales.

Pueden darse los siguientes casos de abortos:

1\%. aborto debido a causa patológica en la madre o en el feto, en cuyo caso no hay delito alguno;

2\%, aborto causado por traumatismo no imputable, tampoco hay delito;

$3^{\circ}$, aborio provocado intencionalmente. Nuestro Código Penal castiga con severidad este delito. En sus Arts. 160 y 161 considera dos casos: cuando la mujer ha prestado su consentimiento $\mathrm{Y}$ cuando no ha consentido en la maniobra abortiva. El aborto es un delito en el que, por regla general, la mujer es empujada a realizarlo y en tal situación necesita la ayuda aje$r_{1} \alpha$ para consumar la expulsión del feto. Esta ayuda se manifiesta tanto por la sugerencia primera hasta alcanzar su consentimiento, cuanto por la materialidad de proporcionar las pastillas abortivas o llevarla donde el empírico o profesionál y abonar los honorarios. Es tan decisiva esta cola. 
boración que la ley, estimando que sin ella no podría realizarse el delito, considera autores a quienes colaboran tan eficazmente en su perpetración. Es menos frecuente que sea la propia mujer quien se practique el aborto, en cuyo caso también se castiga conforme al Ärt. 159.

$4^{\circ}$, aborto provocado sin intención (culposo o preter-intencional). Por regla general no es castigado, excepto el caso de que constare el estado de embarazo de la mujer o éste fuere notorio. (art. 164 del Código Penal).

$5 \%$ El aborto terapéutico está exento de pena en nuestro código, exigiendo como condición esencial que se realice para salvar la vida de la madre o para evitarle un "mal grave y permanente" en su salud. La ciencia ha establecido que no existen casos de alumbramiento en los cuales la salud de la madre peligre de manera absoluta y el parto signifique su muerte. Ya no existe el tremendo dilema de escoger entre la vida de la madre o la del hijo. En cuanto al mal grave y permanente, es concepto impreciso que se presta a muchos abusos. Dados los adelantos de la ciencia niédico-quirúrgica, estos casos constituyen recuerdos del pasado, que hoy no se dan.

$6^{\circ}, \mathrm{El}$ código no reconoce el aborto terapéutico. De darse, constituye un caso de delito contra la vida, sujeto a castigo.

En cuanto al peritaje médico-legal destinado a comprobar este delito, el art. 182 dice: "En caso de aborto se hará comprobar la preexistencia de la preñez, los signos demostrativos de la expulsión violenta del feto, las causas que la determinaron, los probables autores y las demás circunstancias que sirvan para apreciar el carácter y la gravedad del hecho". Por miala técnica se involucra en este artículo, la pericia con la investigación del Juzgado. Al médico no le compete determinar a los probables autores, lo que es labor del Instructor.

El valor probatorio de esta pericia es decisivo. Es uno de los casos en los cuales la opinión del técnico influirá decisivamente en la del juzgacò. $\mathrm{Si}$ los peritos médicos comprueban la existencia del aborto y así lo ảicen en su dictamen, el juez la tomará en cuenta para la calificación del celito, apreciando además las condiciones personales de culpabilidad del agente.

Punto importante que los peritos deben aclarcar, es distinguir el aborto del delito contra la vida por negligencia que puede ser cometido por la impericia del médico, hecho éste último en el cual falta la intención dolosa. Científicamente es fácil distinguirlo $\mathrm{y}$, por su parte, el juez también lo hará en el curso del proceso, pero contando con la leal colaboración riel perito médico.

f) Otro caso que requiere intervención de peritos médicos, es cuando el inculpado presenta síntomas de Enagenación Mental u otros estados patológicos que alteran su personalidad y restringen o anulan su responsabilidad.

Es importante establecer este hecho porque, conforme al inc. $1^{\circ}$ del art. 85 del Código Penal "están exentos de pena: el que comete el hecho 
punible en estado de eniermdad mental, de idiotez o de una grave alteración de la conciencia y no posee en el momento de obrar la facultad de apreciar el carácter delictuoso de su acto o de determinarse según esta apreciación". Siendo la enagenación mental eximente de pena, es necesario acreditarla de nanera indubitable.

La Medicina Legal no interviene ni puede intervenir en fijar la responsabilidad criminal, por ser asunto propio y exclusivo del Derecho Penal. Fero ofrece el concurso de la ciencia médica para establecer si el inculpaá ha procedido con voluntad y discemimiento, de lo cual se deriva su responsabilidad.

La Psiquiatría Médico-Legal abarca el estudio de todas las cuestiones vinculadas a los alienados delincuentes: estudia las reacciones anti-sociales. delictuosas, provocadas por causa síquica-patológica.

Nuestra ley procesal penal emplea el término "enagenación mental" equivalente a "alienación mental": es la denominación genérica de las enfermedades mentales. Nerio Rojas dá la siguiente definición: "clienación mental es el trastorno general y persistente de las funciones síquicas, cuyo ccrácter patológico es ignorado o mal comprendido por el enfermo, y que impide la adaptación lógica y activa a las normas del medio ambiente, sin provecho para sí mismo ni para la sociedad". Este concepto comprende cuatro elementos: $1^{\circ}$ trastorno intelectual; $2^{\circ}$ falta de auto-conciencia; $3^{\text {p }}$ inadaptabilidad; $4^{\circ}$ ausencia de utilidad. La alienación mental tiene muchas reacciones anti-sociales que generan delitos, pero como carecen de caracidad de imputación no son responsables. De los tres elementos clásicos de la responsabilidad: acción, voluntad de ejecución y sanción legal, falta el segundo, por lo que no es imputable legalmente. Solamente requiere ser internado en un asilo de alienados para su curación.

Cuando en el curso del proceso, el Juez tuviere sospechas de que el inculpado de enagenación mental, de oficio o a petición de parte, lo harú reconocer por dos peritos siquiatras. El informe de. estos peritos, debidamente ratificado, determinará si la instrucción continúa por ser el inculpado responsable total o parcialmente, o si se suspende porque sutre de eno. genación mental.

En este caso al formar convicción en el ánimo del Juez, el peritaje influye en la situación procesal del encausado. El Instructor adquiere certeza sobre un hecho gracias a los peritos, cuyo informe tendrá suma importancia por tratarse de asunto técnico. Eso no significa que los peritos zesuelvan, pues el Juez puede apartarse de su dicho, pero en la práctica ciiaria el informe pericial persuade al Juez y ante el dicho de los técnicos, el juez dó valor legalmente al instrumento de la pericia médico-legal, resolviendo en la forma que ellos indican.

Los artículos del Código que tratan de esta prueba son:

Art. 189: "Cuando hubiere sospechas de que el inculpado sufre enagenación mental $\circ$ de otros estados patológicos que pudieran alterar o modificar su responsabilidad, el juez instructor, de oficio o a petición del defensor o del agente fiscal, mandará reconocerlo por dos peritos siquiatras. El defensor o 
el agente fiscal pueden también nombrar un perito. El juez instructor hará concurrir al inculpado al examen de los peritos".

Art. 190: "Si el juez instructor apreciando las conclusiones del peritaje mental, adquiere la convicción de que el inculpado no es enagenado o de que pasa solo por una perturbación de su conciencia, que no excluye la responsabilidad, aunque la atenúe, declarará en la misma audiencia, que continúe la instrucción. En este caso se elevaró un oficio del incidente al Tribunal Correccional, quion puede, previa vista fiscal, reservarlo para cuando se remita la instrucción $u$ ordenar nuevo reconocimiento, confiar a otro juez la instrucción, o dictar la medida que juzgue conveniente".

Art. 191: "Si por el contrario, el juez instructor se persuade de que el inculfado padece de enagenación mental, previo dictamen del agente fiscal, ordenará su ingreso al asilo de inscmos; y elevará la instrucción al Tribunal Correccional para que resuelva definitivamente".

g) En cuanto a la Técnica Moderna, el art. 194 ofrece amplio campo para su aplicación en el proceso penal, sin otra limitación que la propia finalidad del proceso. El ponente de la Comisión Codificadora Dr. Carlos Zavala Loaiza dice que este artículo deja la puerta abierta "a todos los procesos e influencias de las disciplinas modernas que consideradas en el actual momento inadaptables en el campo penal, puedan aparecer insustituibles en rualquier momento debido a los constantes e inesperados avances de la ciencia en general". Según el autor del código, este artículo es enunciativo, no limitativo. En consecuencia todos los adelantos que la técnica ofrece o Fuede ofrecer en un futuro pueden ser empleados por el Juez Instructor.

La técnica está al servicio del Hombre, quien puede aprovecharla tanto para el bien, como para el mal. Depende del Juez que el uso de mecios científicos en una instrucción redunde en beneficio o en perjuicio de la Justicia.

El Juez no tiene libertad para emplear todos los adelantos de la ciencia moderna. Solamente podrá usar aquellos que coinciden y sirvan a los fines del proceso penal. Cuando el adelanto atente contra esta finalidad v. g. vulnera la dignidad de la persona humana, entonces el Instructor no podrá usarlo, porque desvirtúa la finalidad perseguida por la ley procesal penal.

Aunque el Dr. Zavala Loayza no menciona especialmente el narcoanálisis -tan usado por la policía americana y por la justicia comunistasin embargo se declara contrario a los exámenes sico-análiticos, que son unálogos métodos de exploración del siquismo.

En el caso de drogas de la serie barbitúrica, como el actedrón, el evirpán, el penthotal sódico, el amital sódico, etc. que llevan a un estado de inconciencia con inhibición de las facultades volitivas, la oposición es radical. Estas drogas producen obnubilación de la conciencia, desaparición ce la auto-crítica, deterioro de la voluntad y debilitamiento de los frenos inhibitorios; las ideás afluyen con rapidez, tornándose locuaz el sujeto, pero sumamente sensible a los interrogatorios formulados con habilidad; la 
fantasia se despierta llegando a configurar situaciones en las que no ha intervenido. Este estado de semi-conciencia también lo es de semi-responsabilidad; lo que el sujeto declara bajo la acción de las drogas, está fuera de su control.

El empleo de estas drogas está vedado al Juez Instructor, porque cienta directamente contra la persona humana y - ya lo hemos dicho- nuestra ley procesal presume inocente al inculpado y como tal tiene derechos çue no puede vulnerar.

Toda la teoría de la prueba cae por su base si admitimos como váli. das las declaraciones arrancadas en un estado de semi-conciencia.

La finalidad que revela este artículo es aprovechar la técnica mocierna en todos aquellos aspectos que, sin atentar contra la persona del in. culpado, su empleo pueda arrojar luz en la investigación de la verdad.

Por otra parte, el art. 194 es enunciotivo. Enumera en que casos puede emplearse la técnica. Indica que puede referirse a las huellas digitales, manchas de sangre, trazas, documentos, armas y proyectiles. En ningún momento menciona exámenes de la persona del inculpado ni menos sugiere que pueda ser sometido a la acción de drogas que deterioran sı personalidad. Como ha dicho muy bien un autor, aceptar el empleo de estas crogas, es reducir toda la teoría de la prueba a una jeringuilla.

Dentro de la orientación seguida por la ley procesal penal peruana, el inculpado, como ser humano, tiene derechos que no pueden ser vulneracios por nadie; el magistrado es el primero que debe reconocer estos derechos y el encargado por la ley de hacerlos respetar.

El art. 194, objeto de este comentario, dice: "Para la investigación del hecho que constituye delito o para la identiticación de los culpables, se emplearán todos los medios científicos y técnicos que fuesen posibles, como exámenes de impresiones digitales, de sangre, de manchas, de trazas, de documentos, armas y proyectiles".

h) El último caso de intervención de perito médico lo consigna el art. 195, que dice: "El juez instructor o el Tribunal Correccional puede ordenar, según las circunstancias lo requieran y las posibilidades que existan, el examen del acusado o testigos para determinar sus condiciones fisiológicas, intelectuales y síquicas".

Esta disposición faculta a los jueces para someter a los testigos a determinados exámeries sico-experimentales tendientes a lograr una medi. da dei grado de credibilidad de su testimonio, lo que influirá en el valor probatorio de esta declaración. En cuanto a los inculpados, este examen revestiró carácter muy severo, sirviendo para establecer las condiciones siquicas y mentales de las cuales se puede derivar una mayor o menor responsabilidad. Esta disposición procesal está relacionada con el art. 51 del Código Penal que, al fijar las condiciones de culpabilidad, señala "lax calidad de los móviles honorables o excusables o innobles o fútiles que lo determinaron a delinquir". 
Es facultativo por requerir elementos técnicos capacitados para realizarlos y laboratorios que sirvan de experimentación, lo que no siempre es posible hallarlos.

Estos exámenes sin atentar contra la persona del inculpado ni violor los derechos individuales pueden arrojar luz sobre sus condiciones fisiológicas, síquicas e intelectuales, contribuyendo así a establecer el graäo exacto de su responsabilidad.

\section{III.-CONCLUSIONES.}

Como resultado de las anteriores consideraciones, llegamos a estarlecer las siguientes Conclusiones:

10-El Código de Procedimientos Penales del Perú respeta los derechos individuales del sujeto sometido a la acción de la justicia, a quien presume inocente hasta el momento de la sentencia;

$2^{\circ}$-Frente a problemas técnicos que escapan a sus conocimientos, la ley cutoriza al Juez a nombrar peritos médicos quienes emitirán informe razonado, que deberá ser ratificado, diligencia de suma importancia que se realizará ante el Juez y a la cual podrón concurrir el Agente Fiscal, el inculpado con su defensor y la parte civil; también autoriza a éstas partes a designar un perito médico por su cuenta, cuya opinión ilustrará el debate;

3:-Las conclusiones a que llegue la pericia médico-legal, debidamente ratificada, influirá en el curso del proceso, contribuyendo a que el Juez Instructor se forme convicción sobre el delito;

$4^{\circ}$ - En unos casos, estas conclusiones determinarán la existencia del delito v. g. en caso de aborto; en otros establecerán la gravedad y modalidad del hecho v. g. en el homicidio; en otros determinará la responsabilidad del agente v. $g$. en el caso de la enagenación mental:

$5^{\circ}$-El código autoriza el empleo de los nuevos medios que la técnica ofrece, con la sola excepción de aquellos que, como los barbitúricos, desvirtúan la finalidad del proceso penal, violando los inalienables derechos del individuo;

$6^{\circ}$-Finalmente la ley procesal penal peruana autoriza exámenes sico-experimentales en testigos $y$ acusados; en los primeros para calificar su credibilidad; en los segundos para esclarecer los móviles y establecer Jas condiciones en que se ha perpetrado el delito. 